\title{
Capecitabine/Cisplatin Regimen
}

National Cancer Institute

\section{Source}

National Cancer Institute. Capecitabine/Cisplatin Regimen. NCI Thesaurus. Code

C141506.

A regimen consisting of capecitabine and cisplatin that can be used in the treatment of gastric cancer. 